ISSN 2179-345X

Licenciado sob uma Licença Creative Commons

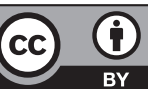

\title{
O direito fundamental ao meio ambiente no Brasil e em São Tomé e Príncipe: um estudo de Direito Comparado ${ }^{1}$
}

\section{The fundamental right to the environment in Brazil and Sao Tome and Principe: a study of comparative law}

\section{Edson Sacramento Tiny das Neves ${ }^{[a]}$, Thiago Pires Oliveira ${ }^{[b]}$}

[a] Mestre em Direito Público pela Universidade Federal da Bahia (UFBA), Bacharel em Direito pela UFBA, jurista santomense, professor titular da Associação Educacional Unyahna, Salvador, BA - Brasil.

[b] Mestrando em Direito pela Universidade Federal da Bahia (UFBA), Especialista em Direito do Estado pela UFBA, Bacharel em Direito pela UFBA, Salvador, BA - Brasil, e-mail: piresol@hotmail.com

\section{Resumo}

Este artigo aborda o direito fundamental ao meio ambiente no ordenamento jurídico-constitucional de dois países lusófonos, o Brasil e São Tomé e Príncipe, de modo a demonstrar de que

1 Este artigo é um aperfeiçoamento de comunicação anteriormente apresentada no 10 Congresso Internacional de Direito Ambiental, ocorrido em meados de 2006 na cidade de São Paulo, Brasil. 
maneira se encontra resguardado o meio ambiente nesses dois países sob a ótica constitucional e analisar os impactos dessa tutela nos dois ordenamentos jurídicos. Assim, iniciou-se este artigo com um estudo comparado das instituições jurídicas no Brasil e em São Tomé e Príncipe. Em seguida, passou-se à análise do direito fundamental ao meio ambiente. Depois, abordou-se o meio ambiente nas Constituições dos dois países. Por fim, concluiu-se que o conceito de meio ambiente não seria um conceito de teoria geral do direito ambiental aplicável a qualquer ordenamento jurídico indistintamente, mas um conceito de direito positivo, pois a concepção de meio ambiente varia de acordo com cada sociedade, considerando as diferentes formas de percepção ambiental dos cidadãos e a realidade socioecológica de cada país.

Palavras-chave: Direito Comparado. Direito Ambiental. Brasil. São Tomé. Príncipe.

\begin{abstract}
This article discusses the fundamental right to environment in the constitutional system of two Lusophone countries, Brazil and Sao Tome and Principe, in order to demonstrate how it is safeguarded the environment in these two countries from the constitutional perspective and analyze the impacts of this protection in both jurisdictions. Thus began this article with a comparative study of legal institutions in Brazil and Sao Tome and Principe. Then came the analysis of the fundamental right to the environment. Then, we dealt with the environment in the constitutions of both countries. Finally, we conclude that the concept of environment would not be a concept of general theory of law applicable to any environmental law alike, but a concept of positive law, since the conception of the environment varies with each company considering the different forms of citizens' environmental awareness and socio-ecological reality of each country.
\end{abstract}

Keywords: Comparative law. Environmental law. Brazil. Sao Tome. Principe.

\title{
Introdução
}

A incorporação das normas internacionais de direitos humanos pelo direito interno das nações é um dos maiores desafios destes 
tempos pós-modernos, época em que instituições internacionais, como a Organização das Nações Unidas (ONU), passam por uma crise de legitimidade, com suas normas sendo questionadas e rejeitadas pelo ordenamento jurídico de diversos países².

Esse desafio trazido pela pós-modernidade ainda se torna mais complexo quando se trata de efetivar na esfera do direito interno os denominados "direitos de terceira geração" ${ }^{3}$, como é o caso do direito humano ao meio ambiente, consagrado pelas Declarações de Estocolmo de 1972 e do Rio de 1992. Esses direitos se encontram cada vez mais positivados pelos países ao redor do Mundo, tanto no âmbito constitucional quanto no infraconstitucional (PRIEUR, 2004, p. 108).

Dessa forma, abordar-se-á o tema do direito humano ao meio ambiente na realidade jurídica de dois países, ex-colônias lusitanas, localizados em dois distintos continentes, a África e a América, mas que partilham a mesma língua oficial, o português, e de laços culturais mais próximos do que se imagina: A República Federativa do Brasil e a República Democrática de São Tomé e Príncipe.

O método abordado será o hipotético-dedutivo, o qual partirá da seguinte hipótese: os ordenamentos jurídicos brasileiro e santomense salvaguardam o meio ambiente e possuem um conceito diferenciado de meio ambiente que exprime a sua realidade sociocultural e ecológica. Utilizar-se-ão a pesquisa bibliográfica e documental para a sistematização dos dados referentes aos dois sistemas jurídicos e a comprovação ou não da hipótese.

A República Democrática de São Tomé e Príncipe é um país insular, de natureza arquipelágica, composto por duas ilhas: São Tomé,

2 Vide o caso da iraniana Sakineh, que na atualidade (julho de 2011) se encontra às vésperas de ser condenada à pena capital de lapidação pela Justiça Iraniana, sanção jurídica prevista pelo ordenamento jurídico iraniano que vem sendo questionado em face das normas internacionais de direitos humanos.

3 Alguns autores, como o brasileiro Antonio Cançado Trindade, questionam a existência da Teoria das Gerações de Direitos formulada por Norberto Bobbio. Todavia, não é objeto deste trabalho analisar essa teoria, sendo mantida a concepção consensualizada pela doutrina quanto ao meio ambiente se encontrar entre os chamados direitos de terceira geração. 
situada junto à linha do Equador; e Príncipe, pequena ilha situada a 150 quilômetros a nordeste de São Tomé. Esse país-arquipélago se encontra geograficamente situado no continente africano, precisamente no Golfo da Guiné, junto à Costa Ocidental da África. Possui uma superfície de 964 $\mathrm{km}^{2}$ e uma população aproximada de 200 mil habitantes (TINY, 2010).

Dentre as principais características ambientais do país, destaca-se a preleção de Brígida Brito, segundo a qual os recursos ambientais santomenses podem ser analisados com base na distinção entre potencialidades florestais e heliotrópicas (BRITO, 2004, p. 1). As potencialidades florestais ${ }^{4}$ consistem na existência de florestas tropicais caracterizadas por uma vegetação exuberante, e em estado virgem, onde habitam diferentes espécies de flora e de fauna, algumas endêmicas e ameaçadas de extinção. A cobertura florestal atinge $95 \%$ da superfície total das ilhas, sendo possível identificarem diferentes áreas arborizadas, em função da altitude e da vegetação (BRITO, 2004, p. 1) .

Essa "casual" preservação do meio ambiente santomense se deve, na realidade, às condições históricas e geográfico-econômicas de São Tomé e Príncipe, como a insularidade, o isolamento e sua pequena dimensão territorial $^{6}$, aliadas com a ausência de indústrias. Essa ausência se dá em virtude da natureza essencialmente agrícola, característica da economia desse país, que passou, durante o Colonialismo português, pelos ciclos da cana-de-açúcar, do café e do cacau (ARAGÃO, 2000, p. 173); somente modificando a matriz agrícola da economia nacional com a descoberta e exploração do petróleo na contemporaneidade (SANDBU, 2004, p. 7).

4 Lei n. 11/1999, de 14 de abril de 1999, Lei de Conservação da Fauna, Flora e das Áreas Protegidas.

5 Em virtude dessa exuberância florestal, o Estado santomense tem buscado criar obôs (parques florestais, na língua fôrro) (BRITO, B. R. Turismo ecológico em São Tomé e Príncipe: da ecopedagogia à preservação ambiental. In: CONGRESSO LUSO-AFRO-BRASILEIRO DE CIÊNCIAS SOCIAIS: A QUESTÃO SOCIAL NO NOVO MILÊNIO, 8., 2004, Coimbra. Anais... Coimbra: Centro de Estudos Sociais; Faculdade de Economia; Universidade de Coimbra, 2004. p. 1).

6 São $1.001 \mathrm{~km}^{2}$ distribuídos por $859 \mathrm{~km}^{2}$ (Ilha de São Tomé) e $142 \mathrm{~km}^{2}$ (Illha de Príncipe) (BRITO, 2004, p. 1). 
Assim, entre os problemas ambientais que se visualizam na República de São Tomé são os impactos ambientais que a indústria petrolífera pode gerar para o país, caso não se realize uma gestão dos recursos petrolíferos de forma sustentável, ou seja, harmonizada com o meio ambiente; a devastação da floresta tropical nacional, decorrente da crescente urbanização no país; e a perda da biodiversidade como consequência dessa devastação e da biopirataria, males ambientais dos países em desenvolvimento portadores de uma rica biodiversidade.

A República Federativa do Brasil é o quinto país em extensão territorial, ocupando $1,7 \%$ da superfície da Terra (quase $6 \%$ das terras emersas) e 47,3\% da América do Sul, e é o sexto país mais populoso do planeta, abrigando mais de 160 milhões de habitantes (BENJAMIN, 1999, p. 75).

Historicamente, o Brasil foi marcado pela degradação intergeracional, pois os ataques praticados contra a natureza por uma geração eram repetidos pela seguinte, em um processo contínuo que se perpetuou por cinco séculos (BENJAMIN, 1999, p. 75). Um dos principais exemplos de aspecto ambiental vitimizado é uma formação florestal tropical latifoliada, denominada Mata Atlântica, que, considerada por botânicos como a floresta com maior biodiversidade por hectare do planeta, encontra-se atualmente com apenas 5\% de sua cobertura original (BENJAMIN, 1999, p. 91).

Na contemporaneidade, o Brasil, apesar da elevada dívida histórica, possui uma posição central nas discussões sobre sustentabilidade do planeta ${ }^{7}$ e problemas ambientais seriíssimos, destacando-se a devastação florestal (destruição da Amazônia, da Mata Atlântica e dos cerrados); a poluição do ar, solo e águas; a contaminação por produtos modificados geneticamente; a biopirataria; e os impactos ambientais causados por grandes empreendimentos, como exemplo temos as hidrelétricas e a transposição de rios.

7 O Brasil possui a maior biodiversidade ( $20 \%$ das espécies existentes) e a maior reserva de água doce do planeta (12\%). Conferir o site do Ministério do Meio Ambiente: <www.mma.gov.br> (BENJAMIN, 1999, p. 75). 


\section{Direito Comparado: Brasil e São Tomé e Príncipe}

O uso da expressão "Direito Comparado" pela comunidade jurídica, muita vezes, prescinde de um rigor técnico. Em virtude dessa circunstância, alguns juristas denominam erroneamente de Direito Comparado apenas a mera menção a uma legislação estrangeira, sem efetuar qualquer estudo crítico-comparativo.

Para os efeitos deste trabalho, define-se como Direito Comparado a "ciência que procura conhecer os diversos ordenamentos jurídicos a partir de estudos comparativos e sistemáticos" (MEIRELES, 2007, p. 34), de modo a comparar não somente dispositivos legais isolados, mas os sistemas jurídicos como um todo, para então passar a analisar alguns institutos do Direito Ambiental Constitucional.

De fato, o Direito de São Tomé e Príncipe somente surgiu como um ordenamento jurídico autônomo e desvinculado politicamente do sistema jurídico português com a independência nacional em 1975, quando fora aprovada a sua Lei Fundamental. Esse país, da mesma forma que no Direito brasileiro, adota o sistema românico-germânico por influência lusitana. A estrutura da República de São Tomé e Príncipe é constituída por um Estado de direito democrático, unitário, tendo como a forma de governo o regime semipresidencialista ${ }^{8}$.

Afirma o constitucionalista português Canotilho (2003) que a fórmula "Estado de Direito Democrático", prevista no artigo $6^{\circ}$ da Constituição santomense, não é inteiramente coincidente com a expressão "Estado Democrático de Direito", prevista no artigo $1^{\circ} \mathrm{da}$ Constituição brasileira. Para que um Estado de Direito Democrático

8 Preleciona o jurista santomense (DAIO, 2010) que "o regime político e constitucional pelo seu mimetismo em relação a antiga metrópole reflecte a concepção do constitucionalismo português e a tipologia do regime 'semi-presidencial' ou um sistema 'misto parlamentar-presidencial'". DAIO, P. As instituições: os poderes do presidente da república. Disponível em: <http://www.cstome.net/ diario/analise_juridica/analise.htm>. Acesso em: 2 set. 2010.

Revista de Direito Econômico e Socioambiental, Curitiba, v. 3, n. 1, p. 253-285, jan./jun. 2012 
tivesse força político-normativa ele precisaria possuir um conjunto de: a) instituições políticas básicas; b) condições econômicas, sociais e culturais favoráveis a essas instituições; c) esquemas político-constitucionais (forma de governo, controle judicial, sistema eleitoral e sistema partidário), bem consolidados no plano institucional, de modo que, se determinado país se declarasse "Estado de Direito Democrático" e não possuísse todos os elementos citados por Canotilho, estaria, na realidade, manifestando o fenômeno da "simbolização constitucional", ou seja, enunciando valores que não seriam aplicados na prática, tornando sua Constituição em mero papel sem força normativa (CANOTILHO, 2003, p. 237).

Já o Direito brasileiro, ao adotar a fórmula do "Estado Democrático de Direito", estaria mais próximo da realidade, ao firmar um padrão legitimatório aceitável, segundo o qual busca rejeitar como forma de organização de sua comunidade política qualquer estrutura totalitária, autoritária ou autocrática (CANOTILHO, 2003, p. 236-237).

O Direito brasileiro se distingue do Direito santomense, principalmente, quanto às formas de governo e de Estado. Esses aspectos influenciam na formação do Direito em qualquer país, pois a depender da forma de Estado, se Federal e Unitário, é que irá ser definido o ordenamento jurídico de um país. Já a diferença quanto à forma de governo repercutirá no papel a ser desempenhado pelos Poderes na produção e cumprimento das leis de um país.

Desse modo, no sistema semipresidencialista, o Poder Executivo será dividido em dois órgãos com cada qual possuindo uma determinada atribuição, definida na Constituição santomense, arts. 68, “a" e "c" e 108. Isso é muito importante para o Direito, principalmente no que se refere à aplicabilidade da norma jurídica, pois um conflito de competências entre órgãos pode resultar na dificuldade de se implementar a lei, com um órgão executivo "empurrando" sua competência para o outro, e este devolvendo tal atribuição e iniciando um "jogo de empurra-empurra". Desse modo, ninguém assume a responsabilidade por efetivar a lei e a sociedade perde 
com esse descaso governamental ${ }^{9}$. Situação diferente ocorre no sistema presidencialista, quando se observa haver uma divisão bem delimitada de funções entre os Poderes, com o chefe do Poder Executivo exercendo seu poder de aplicação imediata da $l \mathrm{i}^{10}$, a qual é produzida pelo Poder Legislativo, por meio de um processo legislativo.

Assim, se um Estado é federal pressupõe-se a existência de uma pluralidade de entes que produzem normas jurídicas e que existe uma divisão de competência legislativa, com cada ente sendo responsável por uma área de atuação. Já se o Estado for unitário, a legislação irá ter como única fonte de produção a República e não haverá uma distribuição de competência legislativa, pois a República é o ente que atribuirá para si o poder legislativo pleno sobre qualquer área.

O Brasil, na qualidade de Republica Federativa, distribui a competência para legislar, a qual pertence ao Poder Legislativo, sobre o meio ambiente em competência privativa, competência exclusiva e competência concorrente, as quais serão exercidas pelo Poder Legislativo de cada ente federativo. Fora algumas questões específicas - como atividade nuclear, Sistema Nacional de Recursos Hídricos - e diretrizes gerais para o desenvolvimento urbano, que são de competência exclusiva (art. 21 da Constituição Brasileira de 1988) da União, e legislar sobre águas, que é privativo (art. 22 da Constituição Brasileira de 1988) também à União, todas as demais competências legislativas na área ambiental serão exercidas de modo concorrente (art. 24 da Constituição de 1988) entre a União e os Estados.

Em São Tomé e Príncipe não há uma determinação constitucional expressa sobre qual órgão será competente para legislar sobre meio

9 No direito de São Tomé e Príncipe, determinadas competências legislativas são atribuídas tanto à Assembleia Nacional (o parlamento do país) quanto ao Governo (chefia do Governo santomense, exercida pelo primeiro-ministro e seu Gabinete). Ex.: segundo o artigo 70 da Constituição, "as leis e os decretos-leis têm igual valor, sem prejuízo da subordinação às correspondentes leis dos decretos-leis publicados no uso da autorização legislativa e dos que desenvolvam as bases gerais dos regimes jurídicos". Sucede que a Lei é a espécie normativa produzida pela Assembleia Nacional, enquanto o Decreto-Lei é a espécie normativa produzida pelo Governo.

10 No Direito brasileiro, a exceção a essa regra é a Medida Provisória. 
ambiente $^{11}$. Desse modo, poderá tanto a Assembleia Nacional como a Assembleia Regional (no caso da Região Autônoma de Príncipe), além das Assembleias Distritais (órgão legislativo local), legislarem sobre o ambiente, desde que obedeçam às diretrizes organizatórias do Estado santomense. Contudo, alguns casos específicos são de competência exclusiva da Assembleia Nacional, conforme se infere do artigo 98, da Constituição de 2003, como legislar sobre crimes ambientais (alínea $\mathrm{k})^{12}$, tributação ambiental (alínea h) ou disciplinar a função ambiental de uma propriedade (alínea g).

\section{O direito fundamental ao meio ambiente}

A preocupação difusa com a proteção dos elementos não humanos que compõem a natureza, ou melhor, a ambiência que circunda o indivíduo, remonta aos períodos mais antigos da história da humanidade. Isso pode ser observado desde a advertência de Platão contra a conspurcação das águas das fontes da pólis grega ${ }^{13}$ até as disposições jurídico-religiosas constantes nos códigos morais de diversas civilizações da Antiguidade,

${ }^{11}$ Conclui Aragão que, embora "seja uma prerrogativa constitucional do Governo e dos Deputados", apenas o Governo tem feito uso do exercício da iniciativa legislativa em São Tomé e Príncipe, graças à norma constitucional constante no art. 111 da Constituição política, de modo que cumpre aos Deputados assumirem sua parcela de responsabilidade (ARAGÃO, A. A. Feitura de leis e legislação ambiental em São Tomé e Príncipe. In: CYSNE, M.; AMADOR, T. (Ed.). Direito do ambiente e redaç̧ão normativa: teoria e prática nos países lusófonos. Gland, Suíça; Cambridge, Reino Unido; Bonn; Alemanha: IUCN, 2000. p. 181).

12 A competência constitucional relacionada no artigo 98 trata da reserva para que a Assembleia Nacional legisle sobre qualquer assunto que verse sobre a matéria penal, tributária e propriedade de bens de produção.

${ }^{13}$ Diz Lobão que: "a abundancia da água é uma das cousas mais necessárias para as cidades e povos de quantas são precisas na república; e assim Platão em suas leis encommenda aos edis que procurem ter copiosas e claras fontes, que não só sirvam aos visinhos, mas que juntamente adornem a cidade. O mesmo advertiu Aristóteles" (LOBÃO. M. de A. e S. de. Tratado prático e compendiário das águas. Lisboa: Imprensa Nacional, 1861. p. 25). 
como o Código de Manu dos povos hindus ${ }^{14}$, o Livro dos Mortos do Império Egípcio, a Torah do povo hebreu, entre outros (GARRIDO, 2004, p. 98-99).

A ideia de direitos humanos era desconhecida na Antiguidade, de modo que filósofos como Platão e Aristóteles chegavam a considerar o estatuto da escravidão como algo natural. Todavia, não houve uma "completa cegueira" em relação a tal ideia, visto que haviam pensadores sofistas e estoicos defendendo a igualdade natural e a ideia de humanidade. Sucede que tal concepção "não conseguiu ultrapassar o plano filosófico e converter-se em categoria jurídica e, muito menos, em medida natural da comunidade social" (CANOTILHO, 2003, p. 380-381).

Desse modo, somente na Idade Moderna surge a noção de direitos humanos, sendo sua origem dividida entre três correntes: a primeira defende seu surgimento com as lutas pela liberdade de religião e crença, encabeçadas por Jellinek e Gregório Peces Barba (CANOTILHO, 2003, p. 383); a segunda defende seu surgimento durante o processo de independência dos Estados Unidos, sendo seu "registro de nascimento" o artigo I da "Declaração de Direitos" do "bom povo da Virgínia", de 16 de julho de 1776 (COMPARATO, 2005, p. 49); a última corrente concebe sua origem no fim do século XVIII, durante a Revolução Francesa, época em que esses revolucionários, influenciados por um Direito natural, de conotação racional-iluminista, criaram um documento jurídico (Declaração Universal dos Direitos do Homem e do Cidadão de 1791) que serviu de referência para todo sistema jurídico que optasse por assegurar certos direitos, inatos ao homem, que seriam invioláveis (PORTANOVA, 2002, p. 682).

Os direitos civis e políticos, após serem consagrados como direitos fundamentais do ser humano, representaram um marco na ocupação do espaço público pelo cidadão. Ocorre que, no decorrer do transcorrer histórico, o mundo passou por muitas transformações. Percebeu-se, então, que não bastava conferir igualdade formal entre os cidadãos nem

${ }^{14}$ O Código de Manu possuía um capítulo específico tratando dos jogos e dos combates de animais, chegando em seu artigo 632 a proibir os jogos em que eram utilizados animais (ALTAVILA, J. de. Origem dos direitos dos povos. 10. ed. São Paulo: Ícone, 2004. p. 79.). 
tentar amenizar as disparidades socioeconômicas produzidas pelo Estado liberal com algumas ações no âmbito dos direitos aos trabalhadores e da seguridade social, se o paradigma civilizatório da humanidade se assenta no desenvolvimento da ciência e dominação da natureza a todo custo, visão essa amparada na falsa crença da "inesgotabilidade dos recursos naturais" (PORTANOVA, 2002, p. 683).

O Direito, conforme já foi mencionado, regulava desde tempos remotos a apropriação dos recursos encontrados no ambiente. Todavia, a conscientização pela classe jurídica quanto à relevância da problemática ecológica e da sua necessária proteção somente advém com a crise ambiental referida. É partir daí que o ser humano, percebendo quão enganosa era a ideia de "inesgotabilidade dos recursos naturais", passa a vislumbrar outro paradigma civilizatório que, por consequência, atingiria uma nova concepção de Direito, visto que institutos tradicionais relacionados a esse saber como propriedade, entre outros, passariam por uma redefinição.

Essa crise civilizacional foi fruto de um modo de produção que, pautado na ideia de progresso, gradualmente ia minando os sistemas sociopolíticos existentes. Nesse sentido, defende Maria Eugenia Palop que a origem do direito humano ao meio ambiente "pode situar-se no contexto de crise de legitimidade do sistema democrático-representativo e dos partidos políticos convencionais que começou naqueles anos" (PALOP, 2004, p. 63).

A crise de legitimidade teria surgido da tensão entre a estrutura econômica capitalista e o sistema democrático que se evidenciou no Estado de Bem-Estar Social (Welfare State), e não da atuação militante dos novos movimentos sociais que detonaram a crise de legitimidade ao sobrecarregar o Estado de Bem-Estar de expectativas, responsabilidades e obrigações ${ }^{15}$.

15 Comenta Palop (2004, p. 63-64) que: "o direito ao meio ambiente vem a introduzir uma forte dinâmica em um contexto de desequilíbrio sistêmico", não implicando o desaparecimento da democracia representativa e sua substituição pela direta, mas a "instalação de uma democracia deliberativa" (o que verifica-se na realidade brasileira com os órgãos colegiados de políticas ambientais: a exemplo de Conama, esfera federal, Cepram, Estado da Bahia, e Comam, município de Salvador, órgãos integrantes do Sistema Nacional de Meio Ambiente, instituído pela Lei Federal 
Entretanto, a mencionada conscientização não fora imediata, começando a ser esboçada, inicialmente, no plano internacional, precisamente no século XIX, quando as Comunidades e os Estados passaram a reconhecer as consequências transfronteiriças das atividades que afetavam a qualidade dos rios e que destruíam a fauna localizada em áreas sobre uma única jurisdição nacional. Somente na década de 1930 ocorreu a primeira decisão, proferida pelo tribunal arbitral que julgou o Trail Smelter Case, o qual reconheceu as consequências transfronteiriças da poluição atmosférica. A primeira legislação adviria somente na década de 1950, também na esfera internacional, com o tratado internacional que regulava a poluição dos oceanos pelo petróleo (SANDS, 2003, p. 4).

De fato, apenas na segunda metade dos anos 1960 é que se tem o início da construção histórica do direito fundamental ao meio ambiente. Carla Amado Gomes afirma que, na realidade, o primeiro reconhecimento do direito humano ao meio ambiente teria sido feito com a aprovação do Pacto Internacional dos Direitos Econômicos, Sociais e Culturais em 1966, o qual estabeleceu "dever de promoção da qualidade do meio ambiente por parte dos Estados” (GOMES, 1999, p. 44-45).

Já, segundo o jurista argentino Santiago Felgueras, tal direito teria seu "embrião" em um encontro ocorrido dois anos depois, conforme a seguinte transcrição:

em 1968, a Assembléia Geral reconheceu a ameaça contra os direitos fundamentais dos seres humanos imposta pelas mudanças tecnológicas. No mesmo ano, a Organização das Nações Unidas para a Educação, a Ciência e a Cultura (Unesco) organizou a Conferencia Intergovernamental de Especialistas sobre as Bases Científicas para o Uso Racional e a Conservação dos Recursos na Biosfera. Esta foi considerada como uma das primeiras iniciativas relacionadas com o

n. 6.938/81); e a "anteposição da democracia a determinados objetivos econômicos", o que se verifica com a popularização do conceito de desenvolvimento sustentável nas mais diferentes instâncias globais, de modo que o direito ao meio ambiente não rechaçaria integralmente o capitalismo, mas pretenderia corrigir seriamente os seus erros, sem se coadunar com uma guinada ao modo de produção socialista, tal como defendem setores "eco-marxistas". 
nascimento do direito a um meio ambiente saudável (FELGUERAS, 1996, p. 32-33, tradução nossa).

Tais ocorrências, a despeito de demonstrarem tanto o dever estatal de proteger o meio ambiente, inter-relacionando-o com a saúde pública, como o faz o Pacto de 1966, quanto os riscos advindos do avanço tecnológico que estavam pairando sobre o exercício dos direitos fundamentais, conforme reconhecimento feito pela Assembleia Geral da ONU em 1968, deixam perceptível que nos mencionados fatos históricos não houve o reconhecimento institucional do meio ambiente como um direito humano a ser resguardado.

Todavia, isso não impediu que os países e as comunidades regionais, sensibilizados com a conjuntura surgida na década de 1960, que clamava por uma tutela do meio ambiente, começassem a inseri-lo como um tema de relevo da comunidade política. Nesse sentido, foi promulgada a primeira lei contemporânea enfocada na proteção ao meio ambiente, fruto do despertar ecológico dos anos 1960, que veio antes da consagração, no plano normativo, do direito humano ao meio ambiente. Trata-se da Environmental Protection Act (EPA), diploma legal norte-americano que entrou em vigor em $1^{\circ}$ de janeiro de 1970 , pouco antes da Conferência de Estocolmo de 1972 (MATEO, 1998, p. 35).

A construção histórica do reconhecimento institucional do direito humano ao meio ambiente somente aconteceu em 1972, durante a Primeira Conferência Internacional sobre o Meio Ambiente e Desenvolvimento, ocorrida em Estocolmo (Suécia). Essa conferência resultou na Declaração de Estocolmo sobre o Ambiente Humano de 1972, importante documento jurídico internacional que proporcionou, em seu princípio n. 1 , o reconhecimento do direito humano ao meio ambiente ${ }^{16}$.

16 Esta é a redação do princípio 1, que prevê tal direito humano: "o homem tem o direito fundamental à liberdade, à igualdade e ao desfrute de condições de vida adequadas, em um meio ambiente de qualidade tal que lhe permita levar uma vida digna, gozar de bem-estar e é portador solene de obrigação de proteger e melhorar o meio ambiente, para as gerações presentes e futuras. A esse respeito, as políticas que promovem ou perpetuam o 'apartheid', a segregação racial, a 
Desde então, o meio ambiente foi sendo incorporado cada vez mais como um valor necessário para as comunidades políticas e para a própria sociedade internacional. É reflexo desse reconhecimento uma decisão da Corte Internacional de Justiça, de 1986, na qual era reconhecido o direito ao meio ambiente como um autêntico direito a ser exercido e protegido (SANDS, 2003, p. 295).

Nessa progressão histórica, surgiu a Declaração de Haia sobre o meio ambiente, de 1989, que reconhecia "o dever fundamental de preservar o ecossistema" e o "direito a viver com dignidade em um ambiente global viável, e o dever consequente da comunidade de nações [...] fazer tudo que puder ser feito para preservar a qualidade do meio ambiente" (SANDS, 2003, p. 295, tradução nossa).

Em 1990, a Comissão de Direitos Humanos da ONU adotou a Resolução n. 1990/41, entitulada Human Rights and the Environment (Direitos Humanos e Meio Ambiente), na qual reafirmava a relação entre a preservação do meio ambiente e a promoção dos direitos humanos (BOSSELMANN, 2001, p. 38). Em 1992, foi proclamada, durante a Conferência das Nações Unidas para o Meio Ambiente e Desenvolvimento, ocorrida no Rio de Janeiro e conhecida como ECO-92, uma nova Declaração, que reinterpretava os princípios previstos na Declaração de Estocolmo sob a ótica do desenvolvimento sustentável.

Assim ocorreu com o direito humano ao meio ambiente, pois este continuou a ser consagrado no princípio 1 da Declaração do Rio de Janeiro sobre o Meio Ambiente e Desenvolvimento, todavia de forma indireta, diferente do constante na Declaração de Estocolmo, conforme se infere da seguinte transcrição: "os seres humanos estão no centro das preocupações com o desenvolvimento sustentável. Têm direito a uma vida saudável e produtiva, em harmonia com a natureza" (SILVA, 2004, p. 59).

discriminação, a opressão colonial e outras formas de opressão e de dominação estrangeira permanecem condenadas e devem ser eliminadas" (DEL POZO, M. F. El derecho humano a un medio ambiente adecuado. Bilbao: Universidad de Deusto, 2000. p. 32-33). 
A Declaração do Rio possui forte carga antropocêntrica norteando seus princípios. Visando a contrastar com esse documento, a comunidade internacional lançou em 1997 a Carta da Terra, documento que, rejeitando o antropocentrismo "escancarado" da Declaração do Rio de Janeiro, defendia a sustentabilidade baseada no princípio ecocêntrico "respeito à Terra e toda a vida". Esse documento viria a ser adotado pela ONU em 2002, conjuntamente com o Compromisso para o Desenvolvimento Sustentável ${ }^{17}$.

O direito ao meio ambiente tem se expandido tão rapidamente no cenário internacional que, atualmente, ele integra a preocupação dos mais diversos organismos internacionais desde o Programa das Nações Unidas para o Meio Ambiente (PNUMA) até o Alto Comissariado das Nações Unidas para Refugiados (ACNUR) (TRINDADE, 1992, p. 14-15).

Além da concepção transversal da temática ambiental junto aos organismos internacionais, cumpre salientar o reconhecimento desse direito fundamental pelo Direito Internacional Público, conforme se observa pela posição do Tribunal Internacional de Haia. Esse tribunal já entende que "o meio ambiente não é uma abstração, mas um espaço onde vivem os seres humanos, pelo qual dependem, a qualidade de sua vida, sua saúde e que compreende as gerações futuras" (PRIEUR, 2004, p. 105). Isso também se observa pelo fato de que existem inúmeros tratados internacionais (no ano de 1992, já eram mais de 150) que vêm sendo celebrados sobre a matéria ambiental (TOLBA, 1992, p. 267).

Diversos Estados têm tomado medidas relacionando o meio ambiente com a salvaguarda dos direitos fundamentais. Até 2003, as constituições de pelo menos cem países já reconheciam expressamente o direito ao meio ambiente limpo ou saudável (SANDS, 2003, p. 296).

17 De fato, a Carta da Terra foi adotada durante a "Rio + 10", nome popularizado da Conferência Mundial sobre Desenvolvimento Sustentável ocorrida em Johannesburgo, África do Sul, em 2002 (BOSSELMANN, K. Human Rights and the environment: environmental justice and legal process. Available at: <http://www.ais.up.ac.za/health/blocks/HET870/Fundamentalprinciples.pdf>. Access in: 29 Dec. 2011. p. 38). 
Exposta a parte histórica, conceitua-se o direito humano ao meio ambiente, direito fundamental de terceira geração, como o "direito de todas as pessoas e todos os povos a desfrutar de um meio ambiente saudável adequado para o seu desenvolvimento" (DEL POZO, 2000, p. 32).

Existe uma estreita relação entre o direito ao meio ambiente com diversos outros direitos fundamentais, destacando-se o direito à vida e o direito à saúde, já reconhecidos pela doutrina jurídica, enquanto outros ainda buscam consolidação doutrinária, como o direito à paz e o direito ao desenvolvimento (DEL POZO, 2000, p. 16).

Santiago Felgueras aponta dois fatores que demonstram a intrínseca interação entre os direitos humanos e o meio ambiente, como o fato de que a deterioração deste podia chegar a impedir o gozo de direitos já reconhecidos. Desse modo, a ideia de um direito autônomo ao meio ambiente sadio ganhou corpo à medida que se percebia a velocidade e a intensidade da deterioração do ambiente (FELGUERAS, p. 1996, p. 17).

Observa-se que meio ambiente é uma condição fundamental para o desenvolvimento da vida, pois esta somente pode existir em um espaço que contenha certos elementos, como a água, o ar e o solo, dotados com suas propriedades naturais de uma forma integral. Contudo, com a degradação, esses elementos sofrem modificações em suas propriedades naturais, dificultando o desenvolvimento da vida naquele espaço.

O direito à vida, proclamado pelos artigos $3^{\circ}$ e 25, da Declaração Universal dos Direitos Humanos de 1948, compreende dois aspectos: um individual, que é o direito de todo ser humano a não ser privado de sua vida; e outro social, que é o direito a um nível de vida adequado a ser promovido pelo Estado. Dentro dessa perspectiva, salienta Mercedes Del Pozo que "o direito a um meio ambiente saudável aparece como uma extensão do direito à vida, já que salvaguarda a própria vida humana propiciando a base para a existência física e de saúde de todos os seres humanos, assim como uma qualidade e condições de vida dignas" (DEL POZO, 2000, p. 49-50, tradução nossa).

O direito ao meio ambiente ecologicamente equilibrado é a concretização do direito fundamental à vida. O direito à vida, que se encontra 
resguardado tanto no artigo 22 da Constituição santomense quanto no art. $5^{\circ}$, caput, da Constituição brasileira, é um direito fundamental básico que, em face de sua abstratividade, necessita de algo que o materialize. Esse algo é o que entendemos como direitos derivados do direito humano à vida, tais como o direito à integridade física, o direito à saúde e o direito ao meio ambiente, visto que sem eles, é impossível a sobrevivência do ser humano como organismo vivo (OLIVEIRA; NEVES, 2006, p. 127-128).

São muitas as objeções doutrinárias ao reconhecimento do direito ao meio ambiente no rol dos direitos fundamentais. Muitos autores se recusam a reconhecê-lo, assim como outros "novos direitos", em virtude do receio doutrinário de que surja uma "inflação de direitos" na área dos direitos humanos, a qual debilitaria o movimento dos direitos humanos, ao impedir a devida proteção não somente dos novos direitos como dos já reconhecidos (FELGUERAS, 1996, p. 39). Isso sem contar a questão das denominadas "reclamações frívolas", que segundo Philip Alston vêm buscando se firmar como direitos humanos, junto a problemas éticos fundamentais (ASTON apud FELGUEIRAS, 1996, p. 39-40).

Reconhecer o direito fundamental ao meio ambiente não implica a prevalência de um direito sobre os demais, mas a igualdade entre direitos fundamentais (não importando se são de primeira, segunda ou terceira geração), conforme nos amparamos na seguinte posição do professor francês Prieur (2004, p. 110, tradução nossa):

de qualquer maneira, a consagração constitucional do meio ambiente não é evidentemente a afirmação de uma preeminência do ambiente sobre os outros direitos fundamentais e sobre os outros interesses protegidos. Ele é o reconhecimento de uma igualdade de direitos fundamentais conduzindo, no caso concreto, e sobre o controle dos juizes, a arbitrar entre os direitos existentes no mesmo valor jurídico.

Em caso de conflitos entre o direito fundamental ao meio ambiente e outros direitos fundamentais, é imprescindível o uso da técnica da ponderação de bens, de modo a sopesar no conflito entre princípios constitucionais qual deverá prevalecer. 
A resolução de tais conflitos ou "casos de tensão", segundo Ossenbuehl, é uma tarefa que a Hermenêutica Constitucional tem se debruçado, seja fomentando uma "querela metodológica" da interpretação da constituição, correspondente à disputa entre os diversos métodos (CANOTILHO, 2003, p. 1210), seja buscando uma sistematização para tal questão sob uma técnica decisória: a ponderação de bens. Esta é definida por Larenz (2005) nos seguintes termos:

a «ponderação de bens no caso concreto» é um método de desenvolvimento do Direito, pois que serve para solucionar colisões de normas para as quais falta uma regra expressa na lei -, para delimitar umas das outras as esferas de aplicação das normas que se entrecruzam e, com isso, concretizar os direitos cujo âmbito, como o do direito geral de personalidade, ficou em aberto (LARENZ, 2005, p. 587).

Conforme a conceituação feita por Larenz (2005), a técnica da ponderação de bens constitui um importante paradigma, do qual se serve a hermenêutica contemporânea, para efetuar a decibilidade dos conflitos, questão central da dogmática jurídica (FERRAZ Jr., 1991, p. 88).

Sobre a ponderação (abwagung) ou balanceamento (balancing) de bens jurídicos, preleciona Canotilho (2003, p. 1221) que a "agitação metódica e teórica em torno do método de balanceamento ou ponderação no direito constitucional não é uma 'moda' ou um capricho dos cultores de direito constitucional".

Haveria diversas razões para tal "viragem metodológica”, dentre elas cabe destacar: a) inexistência de uma ordenação de balanceamento dos bens conflituantes de modo a obter uma norma de decisão situativa, isto é, uma norma de decisão adotada às circunstâncias do caso concreto; b) formatação principal da maioria das normas de direito constitucional (sobretudo aquelas consagradoras de direitos fundamentais), o que implica, em caso de conflito, tarefas de "concordância", "balanceamento", "pesagem", "ponderação" típicas dos modos de resolução de colisões entre princípios (que não se reconduzem a alternativas radicais de all or nothing); c) "fractura da unidade de valores de uma comunidade que obriga 
a leituras várias dos conflitos de bens, impondo uma cuidadosa análise dos bens em presença e uma fundamentação rigorosa do balanceamento efectuado para a solução dos conflitos" (CANOTILHO, 2003, p. 1221).

A ponderação de bens se afigura um importante mecanismo na resolução de controvérsias cada vez mais constantes nesta complexa civilização, que é a que tem sido forjada nestes tempos pós-modernos (BARCELLOS, 2005, p. 7-8). Deve ser observado que o direito fundamental ao ambiente ecologicamente equilibrado, consagrado no artigo 49 da Constituição santomense ${ }^{18}$, é reafirmado pela legislação infraconstitucional, conforme se observa no artigo $2^{\circ}$ da Lei de Bases do Ambiente (Lei n. $10.257 / 2001)^{19}$, exposto a seguir:

Artigo $2^{\circ}$ Direito ao Ambiente

1. Todos os cidadãos têm direito a um ambiente humano e ecologicamente equilibrado e o dever de o defender.

2. Incumbe ao Estado, por meio de organismos próprios e por apelo a iniciativas populares e comunitárias, promover a melhoria da qualidade de vida, individual e colectiva dos cidadãos.

Em face disso, inferimos ser o direito humano ao meio ambiente, na realidade santomense, um direito que não enfrenta nenhum obstáculo jurídico para ser implementado, de modo que se ele não é aplicado na realidade do país é porque o órgão executor da norma (Governo, Governo Regional ou Câmara Distrital) está se omitindo em cumprir com a lei.

No Brasil, o direito ao meio ambiente ecologicamente equilibrado se encontra amparado no art. $5^{\circ}$, da $\mathrm{CF} / 88$, que prevê: "todos têm direito ao meio ambiente ecologicamente equilibrado, bem de uso comum do

18 Está previsto no artigo 49 (1) da Constituição de São Tomé e Príncipe: "todos têm direito à habitação e a um ambiente de vida humana e o dever de o defender". Ou seja, trata-se de um direito-dever tal como é concebido pelo caput do art. 225 da Constituição Federal do Brasil.

19 Diz o jurista santomense Aragão (2000, p. 178) sobre a Lei de Bases do Ambiente de São Tomé e Príncipe que "constitui um enorme avanço no direito positivo são-tomense", de modo que a aprovação desse instrumento jurídico iniciou uma nova era no ordenamento jurídico santomense, em matéria ambiental. 
povo e essencial à sadia qualidade de vida, impondo-se ao Poder Público e à coletividade o dever de defendê-lo e preservá-lo para as presentes e futuras gerações".

Contudo, não há remissão expressa ao direito humano ao ambiente na legislação ordinária brasileira. Isso se deve ao fato de que após a Constituição Federal, praticamente, somente foram promulgados diplomas legais específicos a determinados setores do meio ambiente ${ }^{20}$, enquanto a principal lei que disciplina o meio ambiente em geral é anterior à $C F / 88$, ou seja, é a Lei n. 6.938/81, que estabelece a Política Nacional de Meio Ambiente e que seria o diploma legal mais adequado para reconhecer no plano infraconstitucional o direito fundamental ao meio ambiente.

\section{A temática "meio ambiente" nas Constituições políticas dos dois países}

De acordo com Antonio Herman Benjamin, ministro do STJ, a presença do meio ambiente no texto constitucional ocorreu em três etapas:

a) etapa preliminar: quando a proteção constitucional ao ambiente ainda não reconhecia o meio ambiente como direito fundamental. Nesse momento, tal tutela foi emplacada pelas constituições de algumas nações, então socialistas, como a Bulgária e a União Soviética, que adotou tais normas somente em caráter simbólico;

20 Por exemplo, em 1989 foram promulgadas duas leis: a 7.802, relacionada ao destino final de embalagens; e a Lei n. 7.804, que modificou trechos da Lei 6.981, mas não a alterou substancialmente, como talvez já necessitasse. Em 1995, veio a Lei n. 8.974, de biossegurança; em 1997, promulgou-se a Lei n. 9.433, relativa aos recursos hídricos; em 1998, tipificaram-se os crimes ambientais; em 1999, tratou-se das unidades de conservação; em 2001, do Estatuto das Cidades; em 2005, da lei sobre biossegurança, a Lei n. 11.105; em 2006, da Lei da Mata Atlântica; em 2007, da Lei de Saneamento Básico; em 2009, da Lei da Política Nacional de Mudanças Climáticas; e, em 2010, da Lei da Política Nacional de Gerenciamento de Resíduos Sólidos.

Revista de Direito Econômico e Socioambiental, Curitiba, v. 3, n. 1, p. 253-285, jan./jun. 2012 
b) primeiro momento de constitucionalização do direito ambiental: a partir da década de 1970, com a sua adoção pela Constituição da Grécia (1975), Portugal (1976) e Espanha (1978), países que efetivamente consagraram o direito humano ao meio ambiente em seus textos constitucionais, como a exceção da Grécia, e que ao acabarem de se libertar de regimes ditatoriais (BENJAMIN, 2002, p. 89-90) buscaram dar seu "grito de liberdade" com a promoção das mais diversas modalidades de direitos humanos existentes, como resposta à opressão que haviam sofrido sob o jugo de regimes políticos autocráticos, como o "Regime dos Coronéis" gregos, a lusitana ditadura salazarista e a ditadura espanhola de Francisco Franco;

c) segundo momento de constitucionalização do direito ambiental: iniciado depois da Conferência do Meio Ambiente e Desenvolvimento, ocorrida na cidade do Rio de Janeiro em 1992, com outros países adotando os conceitos trazidos pela ECO-92, como o conceito de desenvolvimento sustentável, em seus diplomas constitucionais, como é o caso da Constituição argentina de 1994 (BENJAMIN, 2002, p. 90).

A inserção do direito ao meio ambiente nos ordenamentos jurídicos dos diversos países sucede sob duas formas: a) iniciando-se com a positivação pelo direito positivo infraconstitucional (ou ordem jurídica legalizada) e depois elevando o ambiente à ordem jurídica constitucionalizada; ou b) primeiro o país reconhece em sua constituição a proteção ao meio ambiente (ou ordem jurídica constitucionalizada) e depois promulga um arcabouço legislativo adequado para a inserção do ambiente na ordem jurídica legalizada (BENJAMIN, 2002, p. 101).

No primeiro modelo, com a introdução pelo "legalismo", tem-se o sistema jurídico brasileiro que introduziu o direito ambiental com a edição de uma "lei de comando-e-controle", que era a Lei Federal n. 6.938/81, denominada por Lei da Política Nacional de Meio Ambiente. Somente em 
1988 promulgou-se uma constituição com previsão de normas sobre o meio ambiente.

Já no segundo modelo, com a introdução pelo constitucionalismo, tem-se o exemplo da República de São Tomé e Príncipe, que introduziu o direito do ambiente no direito nacional somente após a promulgação da constituição de 1990, o que foi reafirmado pela nova Constituição de 2003. Somente no ano de 1998, oito anos após a recepção constitucional, o Estado santomense aprovou uma lei de comando-e-controle, denominada Lei de Bases do Ambiente.

Ainda, o jurista brasileiro Antonio Herman Benjamin (2002), abordando a questão da conveniência da proteção constitucional do ambiente, sistematiza vantagens, as quais se subdividiriam em benefícios de "caráter substantivo" e benefícios externos, e os riscos da constitucionalização do meio ambiente.

Seriam benefícios da constitucionalização de caráter substantivo aqueles que "reorganizam a equação dos direitos e deveres que caracteriza a ordem jurídica", sendo enumerados os seguintes: a) estabelecimento do "dever de não degradar"; b) elevação da tutela ambiental ao nível de "direito fundamental"; c) limitação do direito de propriedade; d) legitimação da intervenção do Estado em favor do ambiente; e e) legitimação, tanto do cidadão quanto da sociedade civil, para agir em defesa do meio ambiente, inclusive por meio de ações coletivas (BENJAMIN, 2002, p. 93-95).

Consideram-se benefícios externos ou formais aqueles relacionados à "afirmação concreta ou implementação das normas de tutela ambiental”, os quais são enumerados por Benjamin da seguinte forma: a) posição dorsal da norma constitucional do ambiente no ordenamento jurídico; b) segurança normativa; c) "paradigma da constitucionalidade ambiental"; d) "permitir o controle de constitucionalidade de atos normativos hierarquicamente inferiores (controle formal e material)"; e e) guia para a (re)leitura do direito positivo nacional (BENJAMIN, 2002, p. 95-97).

Já os riscos decorrentes do processo de inserção do ambiente no texto constitucional são: a) "perigos da constitucionalização de 
conceitos, direitos e obrigações insuficiente amadurecidos, mal-compreendidos ou até incorretos ou superados"; b) dificuldade de atualização das normas, não acompanhando o dinamismo do direito ambiental; e c) surgimento no ordenamento de normas constitucionais retóricas (BENJAMIN, 2002, p. 97-98).

\section{Conceito de meio ambiente}

O meio ambiente não é conceituado diretamente por nenhuma das duas Constituições, tanto a brasileira quanto a santomense. Desse modo, o significado jurídico de meio ambiente para o ordenamento jurídico dos dois países deverá ser previsto nas leis infraconstitucionais ${ }^{21} \mathrm{e}$ em definições formuladas pela doutrina.

De acordo com o jurista brasileiro José Afonso da Silva, o meio ambiente seria "a interação do conjunto de elementos naturais, artificiais e culturais que propiciam o desenvolvimento equilibrado da vida em todas as suas formas" (SILVA, 2004, p. 20).

O meio ambiente reúne, conforme a exposição do autor anteriormente citado, três aspectos básicos: o natural, o artificial e o cultural. O natural compreende a interação dos seres vivos e seu meio, onde se daria a correlação recíproca entre os seres e as relações destes com o ambiente físico que ocupam. Em face dessa afirmação, José Afonso da Silva entende que o conceito de meio ambiente exposto no art. $3^{\circ}$ da Lei

${ }^{21}$ No Direito brasileiro, o conceito legal de meio ambiente está previsto no art. $3^{\circ}$ da Lei n. 6.938/81, que estabelece a Política Nacional do Meio Ambiente. Já no Direito santomense, esse conceito encontra-se previsto no artigo 17 da Lei n. 10.257/1999, de 29 de dezembro de 1999, a qual define a base da política de ambiente para o desenvolvimento sustentável da Republica Democrática de São Tomé e Príncipe. 
brasileira n. $6.938 / 81^{22}$ é restrito à noção de meio ambiente natural ${ }^{23}$. Já o direito santomense prevê o conceito legal de meio ambiente no artigo 17 da Lei n. 10.257/2001, de 29 de dezembro de 1998, que estabelece as bases do ambiente na república santomense ${ }^{24}$.

Confrontado o conceito legal de ambiente previsto no Direito brasileiro com o do Direito santomense percebe-se que a controvérsia sobre o conceito de meio ambiente existente no Direito brasileiro não se aplica à realidade de São Tomé e Príncipe, pois o conceito legal desse país é tecnicamente mais adequado que o existente no Brasil, não apresentando a conceituação ambígua existente no Direito brasileiro. Para tanto, leva-se em conta que a função do direito ambiental não seria somente proteger a natureza intocada, mas "colocar a vida saudável como postulado básico a ser garantido a todos cidadãos", o que implica a compatibilização entre os conflitos de progresso econômico com a conservação da natureza (DELGADO, 2002, p. 20).

Comparando-se os dois conceitos expostos pela legislação infraconstitucional, entende-se que o conceito de meio ambiente não seria um conceito de Teoria Geral do Direito Ambiental, aplicável a qualquer país. Seria sim um conceito de Direito positivo, pois a concepção de meio ambiente de uma população variará de acordo com sua percepção ambiental acerca da realidade socioecológica em que se encontra inserida (OLIVEIRA; NEVES, 2006, p. 134).

${ }^{22}$ Segundo o art. 3ำ, inciso I, da Lei brasileira n. 6.938/81: "meio ambiente, o conjunto de condições, leis, influências e interações de ordem física, química e biológica, que permite, abriga e rege a vida em todas as suas formas".

${ }^{23}$ Contrariamente à posição defendida por Silva (2004), o jurista brasileiro Milaré entende que o conceito legal de meio ambiente previsto na Lei brasileira n. 6.938/81 contempla todos os aspectos do ambiente e não somente o aspecto natural. Vide: MILARÉ, E. Direito do ambiente. São Paulo: Revista dos Tribunais, 2000. p. 110.

24 "Artigo 17. Ambiente é um conjunto dos sistemas físicos, químicos, biológicos e suas relações factores económico, sociais e culturais, com efeito, directo ou indirecto, mediato ou imediato, sobre os seres vivos e a qualidade de vida do homem".

Revista de Direito Econômico e Socioambiental, Curitiba, v. 3, n. 1, p. 253-285, jan./jun. 2012 


\section{O texto constitucional nos dois ordenamentos jurídicos}

A inserção do ambiente em um texto constitucional ocorre sobre distintas normas. Assim, pode haver de existirem diversas normas constitucionais adotando os mais distintos recortes constitucionais ao prever algum tipo de proteção ao meio ambiente. Visando a sistematizar tais normas, adotar-se-á uma classificação baseada na obra de Horta (1995). De acordo com esse saudoso constitucionalista mineiro, existem quatro tipos de normas constitucionais que lidam com a questão ambiental: a) regras de garantia; b) regras de competência; c) regras gerais; e d) regras específicas (HORTA, 1995, p. 308).

No entanto, entendendo-se que as normas constitucionais relativas ao meio ambiente abarcam outras em que não há a menção expressa à locação "meio ambiente", como é o caso das normas existentes nos artigos 182 e 183, relativas ao meio ambiente urbano, ou as existentes nos artigos 215 e 216, relacionadas ao meio ambiente cultural, sugere-se denominar as "regras gerais" por "regras esparsas", pois atenderia melhor ao conceito de meio ambiente consagrado pela doutrina no Direito Ambiental contemporâneo.

Assim, baseando-se em Horta (1995), existem quatro modalidades normativas no Direito Constitucional Ambiental que são:

a) as "regras de garantia" enunciam direitos, garantias e mecanismos visando à efetividade do direito constitucional ao ambiente. $\mathrm{Na}$ Constituição brasileira estão previstas no art. $5^{\circ}$, como o direito à vida (caput), a liberdade de associação, que é aplicável às ONGs ambientalistas (inciso XVII), a função social da propriedade (inciso XXIII) e a legitimação do cidadão para a proposição de ação popular em defesa do ambiente (inciso LXIII).

Já na Constituição política de São Tomé e Príncipe, essas regras estão previstas principalmente no artigo 10, alínea “d”, segundo o qual "são objectivos primordiais do Estado: [...] d) Preservar o equilíbrio harmonioso 
da natureza e do ambiente"; no artigo 22, prevendo o direito à vida; e no artigo 35, prevendo o direito à liberdade de associação, o qual dá respaldo para o surgimento de organizações não governamentais ambientalistas.

b) As "regras de competência" delimitam a atuação dos órgãos políticos do Estado em matéria ambiental. Na Constituição Federal do Brasil, estão previstas nos artigos 21, XIX, XX e XXIII (competência exclusiva da União para instituir o Sistema Nacional de Recursos Hídricos, diretrizes gerais para o desenvolvimento urbano e lidar com atividade nuclear); 22, IV (competência privativa da União para legislar sobre água); 23, III, IV, V, VI, VII e IX (competência comum da União, Estados, Distrito Federal e municípios para proteger o patrimônio cultural, o acesso à cultura, meio ambiente, florestas, fauna, flora e promover o saneamento básico); 24, I, VI, VII, VIII (competência concorrente entre a União, Estados e Distrito Federal para legislar sobre direito urbanístico, proteção do meio ambiente, proteção ao patrimônio cultural e responsabilidade por dano ao meio ambiente); 30, VIII e IX (competência dos municípios para promoverem o ordenamento do território e a proteção do patrimônio histórico-cultural local).

$\mathrm{Na}$ Constituição santomense não há uma repartição da matéria ambiental quanto às competências, principalmente em virtude da estrutura unitária do Estado santomense, existindo competências gerais que se subdividem quanto à área de atuação, salvo aquelas competências entendidas como da nação. Assim, existem normas que estabelecem a competência constitucional geral, tanto legislativa quanto administrativa, entre alguns órgãos políticos do Estado, como a Assembleia Nacional (arts. 97 e 98) e o Governo (art. 111), que podem interferir no Direito Ambiental santomense. Em nível nacional, existem as competências legislativas e administrativas regionais e locais da Região Autônoma de Príncipe e das Autarquias Locais (artigo 143(1), da Constituição). 
c) As "regras esparsas" são aquelas que abarcam todas as normas que não costumam ser entendidas como ambientais, pois cuidariam de campos que o senso comum entende como excluídos da preocupação ambiental, como o ordenamento urbano, o meio ambiente do trabalho e o patrimônio cultural. Na Constituição brasileira tem-se essa modalidade de norma constitucional do ambiente nos artigos 170, VI (como princípio da ordem econômica); 182 e 183 (política urbana); 186, II (função social da propriedade rural); 200, VIII (colaboração do Sistema Único de Saúde na proteção do meio ambiente, inclusive o do trabalho); 215 e 216 (cultura); e 225 (capítulo específico do meio ambiente).

Na Constituição da República Democrática de São Tomé e Príncipe, as regras esparsas estão previstas no artigo 43, alínea "d”, condições de higiene no ambiente de trabalho; no artigo 49 (n. 1 - primeira parte e n. 2), no tocante ao ordenamento urbano; e nos artigos 28 e 56 (n. 1-2), normas relativas ao patrimônio cultural.

d) As "regras específicas" são aquelas que tratam expressamente do meio ambiente, que costuma ser confundido com o aspecto natural. Estão expressamente previstas na Constituição Brasileira no seu artigo 225; e na Constituição santomense em seu artigo 49 (n. 1 - segunda parte).

\section{Conclusão}

Comparando-se os dois sistemas jurídico-constitucionais, infere-se que a proteção do meio ambiente é uma realidade inexorável que tende a se irradiar de forma globalizada, não importa o nível de desenvolvimento econômico em que se encontre determinado país. Afinal, o meio ambiente se encontra contextualizado no âmbito de um direito fundamental. 
Isso não significa que reconhecer o direito fundamental ao meio ambiente implica a prevalência de um direito sobre os demais, mas pressupõe a igualdade entre direitos fundamentais que, caso entrem em conflito, deverão ser sopesados com base na técnica da ponderação de bens.

Ademais, as normas constitucionais que lidam com a questão ambiental estão classificadas em quatro modalidades: a) regras de garantia; b) regras de competência; c) regras esparsas; e d) regras específicas.

Por fim, comparando-se os dois conceitos expostos na legislação infraconstitucional brasileira e santomense, entende-se que o conceito de meio ambiente não seria um conceito de Teoria Geral do Direito Ambiental, aplicável a qualquer país, e sim um conceito de Direito positivo, pois a concepção de meio ambiente de uma população variará de acordo com sua percepção ambiental acerca da realidade socioecológica em que se encontra inserida.

\section{Referências}

ALTAVILA, J. de. Origem dos direitos dos povos. 10. ed. São Paulo: Ícone, 2004.

ARAGÃO, A. A. Feitura de leis e legislação ambiental em São Tomé e Príncipe. In: CYSNE, M.; AMADOR, T. (Ed.). Direito do ambiente e redacção normativa: teoria e prática nos países lusófonos. Gland, Suíça; Cambridge, Reino Unido; Bonn, Alemanha: IUCN, 2000. p. 169-172.

BARCELLOS, A. P. de. Ponderação, racionalidade e atividade jurisdicional. Rio de Janeiro: Renovar, 2005.

BENJAMIN, A. H. Introdução ao direito ambiental brasileiro. In: CONGRESSO INTERNACIONAL DE DIREITO AMBIENTAL, 3., 1999, São Paulo. Anais... São Paulo: Imprensa Oficial do Estado de São Paulo, 1999. 
BENJAMIN, A. H. Meio ambiente e constituição: uma primeira abordagem. In: CONGRESSO INTERNACIONAL DE DIREITO AMBIENTAL, 10 ANOS DA ECO92 - O DIREITO E O DESENVOLVIMENTO SUSTENTÁVEL, 6., 2002, São Paulo. Anais... São Paulo: Imprensa Oficial do Estado de São Paulo, 2002.

BOSSELMANN, K. Human rights and the environment: environmental justice and legal process. Available at: <http://www.ais.up.ac.za/health/blocks/ HET870/Fundamentalprinciples.pdf >. Access in: 29 Dec. 2011.

BRASIL. Presidência da República. Lei n. 6.938, de 31 de agosto de 1981. Dispõe sobre a Política Nacional do Meio Ambiente, seus fins e mecanismos de formulação e aplicação, e dá outras providências. Diário Oficial [da] República Federativa do Brasil, Poder Legislativo, Brasília, DF, 1 ago. 1981. Disponível em: <http:// www.planalto.gov.br/ccivil_03/leis/L6938.htm>. Acesso em: 29 dez. 2011.

BRASIL. Presidência da República. Lei n. 7.804, de 18 de julho de 1989. Altera a Lei n. 6.938, de 31 de agosto de 1981, que dispõe sobre a Política Nacional do Meio Ambiente, seus fins e mecanismos de formulação e aplicação, a Lei n. 7.735, de 22 de fevereiro de 1989, a Lei n. 6.803, de 2 de julho de 1980, e dá outras providências. Diário Oficial [da] República Federativa do Brasil, Poder Legislativo, Brasília, DF, 18 jul. 1989. Disponível em: <http://www.planalto.gov. br/ccivil_03/leis/L7804.htm>. Acesso em: 29 dez. 2011.

BRASIL. Lei n. 9.433, de 8 de janeiro de 1997. Institui a Política Nacional de Recursos Hídricos, cria o Sistema Nacional de Gerenciamento de Recursos Hídricos, regulamenta o inciso XIX do art. 21 da Constituição Federal, e altera o art. $1^{\circ}$ da Lei n. 8.001, de 13 de março de 1990, que modificou a Lei n. 7.990, de 28 de dezembro de 1989. Diário Oficial [da] República Federativa do Brasil, Poder Legislativo, Brasília, DF, 8 jan. 1997. Disponível em: <http://www.planalto.gov.br/ccivil_03/leis/L9433.htm>. Acesso em: 23 dez. 2011. 
BRASIL. Presidência da República. Lei n. 10.257, de 10 de julho de 2001. Regulamenta os arts. 182 e 183 da Constituição Federal, estabelece diretrizes gerais da política urbana e dá outras providências. Diário Oficial [da] República Federativa do Brasil, Poder Legislativo, Brasília, DF, 10 jul. 2001. p. 11429. Disponível em: <http://www.planalto.gov.br/ccivil_03/leis/LEIS_2001/L10257. htm>. Acesso em: 20 jul. 2010.

BRASIL. Presidência da República. Lei n. 11.105, de 24 de março de 2005. Regulamenta os incisos II, IV e V do $\S 1^{\circ}$ do art. 225 da Constituição Federal, estabelece normas de segurança e mecanismos de fiscalização de atividades que envolvam organismos geneticamente modificados - OGM e seus derivados, cria o Conselho Nacional de Biossegurança - CNBS, reestrutura a Comissão Técnica Nacional de Biossegurança - CTNBio, dispõe sobre a Política Nacional de Biossegurança - PNB, revoga a Lei n. 8.974, de 5 de janeiro de 1995, e a Medida Provisória n. 2.191-9, de 23 de agosto de 2001, e os arts. $5^{\circ}, 6^{\circ}, 7^{\circ}, 8^{\circ}, 9^{\circ}, 10$ e 16 da Lei n. 10.814, de 15 de dezembro de 2003, e dá outras providências. Diário Oficial [da] República Federativa do Brasil, Poder Legislativo, Brasília, DF, 24 mar. 2005. Disponível em: <http://www.planalto.gov.br/ccivil_03/_ato20042006/2005/lei/l11105.htm>. Acesso em: 16 jul. 2011.

BRITO, B. R. Turismo ecológico em São Tomé e Príncipe: da ecopedagogia à preservação ambiental. In: CONGRESSO LUSO-AFRO-BRASILEIRO DE CIÊNCIAS SOCIAIS: A QUESTÃO SOCIAL NO NOVO MILÊNIO, 8., 2004. Coimbra. Anais... Coimbra: Centro de Estudos Sociais; Faculdade de Economia; Universidade de Coimbra, 2004.

CANOTILHO, J. J. G. Direito constitucional e teoria da constituição. 7. ed. Coimbra: Almedina, 2003.

COMPARATO, F. K. Afirmação histórica dos direitos humanos. 4. ed. São Paulo: Saraiva, 2005.

DAIO, P. As instituições: os poderes do presidente da república. Disponível em: <http://www.cstome.net/diario/analise_juridica/analise.htm>. Acesso em: 2 set. 2010. 
DEL POZO, M. F. El derecho humano a un medio ambiente adecuado. Bilbao: Universidad de Deusto, 2000.

DELGADO, J. A. Aspectos constitucionais do direito ambiental. In: MARTINS, I. G. da S. (Coord.). As vertentes do direito constitucional contemporâneo: estudos em homenagem a Manuel Gonçalves Ferreira Filho. Rio de Janeiro: América Jurídica, 2002. p. 197-227.

FERRAZ Jr., T. S. Introdução ao estudo do direito: técnica, decisão, dominação. São Paulo: Atlas, 1991.

FELGUERAS, S. Derechos humanos y medio ambiente: Buenos Aires: Ad Hoc, 1996.

GARRIDO, M. Apunte para la historia de nuestra visión moral de los animales. In: TAFALLA, M. (Ed.). Los derechos de los animales. Barcelona: Idea Books, 2004. p. 87-105.

GOMES, C. A. O ambiente como objecto e os objectos do direito do ambiente. Revista Jurídica do Urbanismo e do Ambiente, n. 11-12, p. 34-48, 1999.

HORTA, R. M. Constituição e meio ambiente. In: HORTA, R. M. Estudos de direito constitucional. Belo Horizonte: Del Rey, 1995. p. 289-312.

LARENZ, K. Metodologia da ciência do direito. 4. ed. Tradução de José Lamego. Lisboa: Fundação Calouste Gulbenkian, 2005.

LOBÃO. M. A. S. de. Tratado prático e compendiário das águas. Lisboa: Imprensa Nacional, 1861.

MATEO, R. M. Manual de derecho ambiental. 2. ed. Madrid: Trivium, 1998.

MEIRELES, E. Estudo do Direito Comparado. Revista do Curso de Direito da UNIFACS, v. 7, p. 28-42, 2007.

MILARÉ, E. Direito do ambiente. São Paulo: Revista dos Tribunais, 2000. 
OLIVEIRA, T. P.; NEVES, E. S. T. das. O direito humano ao meio ambiente nas Constituições do Brasil e de São Tomé e Príncipe. In: BENJAMIN, A. H. (Org.). Direitos humanos e meio ambiente. In: CONGRESSO INTERNACIONAL DE DIREITO AMBIENTAL, 10., 2006, São Paulo. Anais... São Paulo: Imprensa Oficial do Estado de São Paulo, 2006.

PALOP, M. E. R. De la reivindicación ambiental y los derechos humanos. Venturas y desventuras. In: RIECHMANN, J. (Coord.). Ética ecológica: propuestas para una reorientación. Montevideo: Nordan Comunidad, 2004. p. 59-76.

PORTANOVA, R. Direitos humanos e meio ambiente em perspectiva histórica. In: BENJAMIN, A. H. (Org.). Dez anos da ECO-92 - O direito e o desenvolvimento sustentável. In: CONGRESSO INTERNACIONAL DE DIREITO AMBIENTAL, 6., 2002, São Paulo. Anais... São Paulo: Imprensa Oficial do Estado de São Paulo, 2002. p. 681-694.

PRIEUR, M. Droit de l'homme à l'environnement et développement durable. 2004. Disponível em: <http://www.francophonie-durable.org/documents/ colloque-ouaga-a5-prieur.pdf >. Acesso em: 29 dez. 2011.

SANDBU, M. E. São Tomé pôde por fim à maldição dos recursos naturais da África. Espaço Público, n. 7, 17 ago. 2004. Disponível em: <http://martinsandbu.net/norsk/presse/Publico_170804.pdf>. Acesso em: 29 dez. 2011.

SANDS, P. Principles of international environmental law. 2. ed. Cambridge: Cambridge University Press, 2003.

SILVA, J. A. da. Direito ambiental constitucional. 5. ed. São Paulo: Malheiros, 2004.

TINY, K. N. Conhece São Tomé e Príncipe? Disponível em: <http://www.juristep.com/artigos_/conhece_stp.pdf >. Acesso em: 2 set. 2010. 
TOLBA, M. K. The United Nations Environmental Programme, International Environmental Law and the International Law of Human Rights: message to the inter-american seminar on human rights and the environment. In: TRINDADE, A. A. C. (Ed.). Derechos humanos, desarrollo sostenible y medio ambiente. San José de Costa Rica: Instituto Interamericano de Derechos Humanos, Banco Interamericano de Desarrollo, 1992. p. 266-282.

TRINDADE, A. A. C. (Ed.). Derechos humanos, desarrollo sostenible y medio ambiente. San José de Costa Rica: Instituto Interamericano de Derechos Humanos, Banco Interamericano de Desarrollo, 1992.

Recebido: 02/08/2011

Received: 08/02/2011

Aprovado: 12/07/2012

Approved: 07/12/2012 